\title{
Photodegradation assessment of ciprofloxacin, moxifloxacin, norfloxacin and ofloxacin in the presence of excipients from tablets by UPLC-MS/MS and DSC
}

\author{
Urszula Hubicka ${ }^{1 *}$, Paweł Żmudzki ${ }^{2}$, Przemysław Talik ${ }^{1}$, Barbara Żuromska-Witek ${ }^{1}$ and Jan Krzek ${ }^{1}$
}

\begin{abstract}
Background: Ciprofloxacin (CIP), moxifloxacin (MOX), norfloxacin (NOR) and ofloxacin (OFL), are the antibacterial synthetic drugs, belonging to the fluoroquinolones group. Fluoroquinolones are compounds susceptible to photodegradation process, which may lead to reduction of their antibacterial activity and to induce phototoxicity as a side effect. This paper describes a simple, sensitive UPLC-MS/MS method for the determination of CIP, MOX, NOR and OFL in the presence of photodegradation products.
\end{abstract}

Results: Chromatographic separations were carried out using the Acquity UPLC BEH $C_{18}$ column; $(2.1 \times 100 \mathrm{~mm}$, $1.7 \mu \mathrm{m}$ particle size). The column was maintained at $40^{\circ} \mathrm{C}$, and the following gradient was used: $0 \mathrm{~min}, 95 \%$ of eluent $A$ and $5 \%$ of eluent $B ; 10$ min, $0 \%$ of eluent $A$ and $100 \%$ of eluent $B$, at a flow rate of $0.3 \mathrm{~mL} \mathrm{~min}{ }^{-1}$. Eluent $A$ : $0.1 \%(\mathrm{v} / \mathrm{v})$ formic acid in water; eluent B: $0.1 \%(\mathrm{v} / \mathrm{v})$ formic acid in acetonitrile. The method was validated and all the validation parameters were in the ranges acceptable by the guidelines for analytical method validation. The photodegradation of examined fluoroquinolones in solid phase in the presence of excipients followed kinetic of the first order reaction and depended upon the type of analyzed drugs and coexisting substances. Photodegradation process of analyzed drugs was confirmed by differential scanning calorimetry. In addition, the identification of degradation products was carried out by mass spectrometry.

Conclusion: The developed UPLC-MS/MS method enables the determination of CIP, MOX, NOR and OFL in the presence of photodegradation products and identification of photodegradation products.

Keywords: Ciprofloxacin, Moxifloxacin, Norfloxacin, Ofloxacin, Photodegradation, Kinetic evaluation, Ultra performance liquid chromatography, Tandem mass spectrometry, Differential scanning calorimetry

\section{Background}

Ciprofloxacin (CIP), moxifloxacin (MOX), norfloxacin (NOR) and ofloxacin (OFL), are the antibacterial synthetic drugs, belonging to fluoroquinolones group. Fluoroquinolones exhibit increased antibacterial activity against the Enterobacteriaceae and other Gram-negative bacteria such as Pseudomonas aeruginosa, and exert some activity against certain Gram-positive cocci [1,2]. Among them, MOX also show notable efficacy against atypical

\footnotetext{
* Correspondence: urszula.hubicka@uj.edu.pl

'Department of Inorganic and Analytical Chemistry, Jagiellonian University Medical College, Faculty of Pharmacy, 9 Medyczna Street, 30-688 Kraków, Poland

Full list of author information is available at the end of the article
}

bacteria of Chlamydia spp., Mycoplasma spp., and Legionella spp. genera, bacilli of genus Mycobacterium and anaerobe of Bacteroides and Clostridium genera [3-5].

Fluoroquinolones are compounds susceptible to photodegradation process, which may lead to reduction of their antibacterial activity and to induce phototoxicity as a side effect [6]. In the available literature many papers devoted to the studies of fluoroquinolone photodegradation in solutions can be found [7-10], while only a few relate to photodegradation studies of a substance or of the pharmaceutical preparation in the solid phase [10-13].

The photodegradation process of CIP in solid phase was analyzed by thin layer chromatography method with
(C) Chemistry Central

(c) 2013 Hubicka et al.; licensee Chemistry Central Ltd. This is an Open Access article distributed under the terms of the Creative Commons Attribution License (http://creativecommons.org/licenses/by/2.0), which permits unrestricted use, distribution, and reproduction in any medium, provided the original work is properly cited. 
densitometric detection in the presence and without selected metal ions. Samples were prepared on Petri dishes by evaporation of the test solution to obtain a dry residue. They were exposed to UV radiation within the range from $240 \mathrm{~nm}$ to $280 \mathrm{~nm}$ for $96 \mathrm{~h}$ [11]. Assessed the studies performed it was found that both ion concentration and ion type have an effect on the degradation process that leads to the generation of two photoproducts. The chemical structures of the photodegradation products were identified as follows 7-[(2-aminoethyl)amino] 1-cyclopropyl-6-fluoro-1,4-dihydro-4-oxo-qunoline-3carboxylic acid and 7-amino-1-cyclopropyl-6-fluoro-1,4dihydro-4-oxo-qunoline-3-carboxylic acid [11].

Photostability of MOX after UVA irradiation in solutions and solid phase, with and without participation of $\mathrm{Cu}(\mathrm{II}), \mathrm{Zn}(\mathrm{II}), \mathrm{Al}(\mathrm{III})$, and $\mathrm{Fe}(\mathrm{III})$ was tested. Samples for testing in solid phase were prepared in the same manner as described in a publication on CIP [11]. They were exposed to UVA radiation within the range from $320 \mathrm{~nm}$ to $400 \mathrm{~nm}$ for $15 \mathrm{~h}$ [10]. The studies were carried out by the TLC-densitometric method. In solid phase, all metal ions decreased the photodegradation of MOX. Identification of the degradation three products was performed with LC-MS/MS and ${ }^{1} \mathrm{HNMR}$ identified them as: 1-cyclopropyl6-fluoro-7-amino-8-methoxy-4-oxo-1,4-dihydroquinoline3-carboxylic acid, 1-cyclopropyl-6-fluoro-8-methoxy-4oxo-7-(2-oxo-octahydro-6H-pyrrolo[3,4-b]pyridine-6-yl)-1, 4-dihydroquinoline-3-carboxylic acid, 7-[3-hydroxyamino4-(2-carboxyethyl)pyrrolidin-1-yl]-1- cyclopropyl-6-fluoro-8methoxy-4-oxo-1,4-dihydroquinoline-3-carboxylic acid [10] .

Photodegradation of NOR in solid phase in the presence of different excipients used for making tablets has been studied. The NOR tablets were exposed under direct sunlight, fluorescent light and UV radiation (continuous 254-nm UV lamp), at ambient temperature $\left(25^{\circ} \mathrm{C}\right)$ and $65 \%$ relative humidity. The separation of NOR and its degradation products was achieved isocratically using a Lichrosorb $^{\oplus} \mathrm{C} 8$ chromatographic column $(10 \mu \mathrm{m}, 20 \mathrm{~cm} \times$ $4.6 \mathrm{~mm}$ ) and phosphate buffer solution adjusted to $\mathrm{pH} 3.0$ - acetonitrile $(85: 15, \mathrm{v} / \mathrm{v})$ as the eluent, pumped at a flow rate of $2.0 \mathrm{ml} / \mathrm{min}$. The authors proved that during photodegradation diamineethyl derivative of NOR occurs [12].

The photostability of OFL in the solid state has been investigated. Irradiation was conducted in a chamber SUNTEST CPS + at $30^{\circ} \mathrm{C}$ using xenon lamp $(1.5 \mathrm{~kW})$ equipped with a $6 \mathrm{~mm}$ special glass filter, transmitting light corresponding to exposure behind window-glass (cut-off approximately $310 \mathrm{~nm}$ ). The change in colour of uncoated and film coated OFL tablets and compressed OFL was studied as a function of irradiance level and total exposure energy. The degradation of OFL was quantified by HPLC. The separation of OFL and its two degradation products was achieved using a Symmetry C-18 chromatographic column $(3,5 \mu \mathrm{m}, 100 \mathrm{~mm} \times 4.6 \mathrm{~mm})$. The mobile phase consisted of triethylamine $(4.5 \mathrm{ml})$, double-distilled water $(830 \mathrm{ml})$ and acetonitrile $(140 \mathrm{ml})$. The $\mathrm{pH}$ was adjusted to 2.3 with $85 \% \mathrm{H}_{3} \mathrm{PO}_{4}$ before addition of acetonitrile. The flow rate was $1 \mathrm{ml} / \mathrm{min}$. The structure of two main degradation products of OFL has been postulated from LC-MS analysis [13].

In summary, the existing research concerning the photostability of fluoroquinolones in the solid phase are not a comprehensive but relate of individual substances. The study was performed using different irradiation conditions and exposure time. Only two papers concern the influence of excipients on the photodegradation process. Applied methods such as TLC, HPLC and LC-MS allowed the separation and identification of up to three photodegradation products. In any paper not carried out studies of fluoroquinolones irradiated in the solid phase by DSC.

In the presented paper we have developed and validated an ultra-performance liquid chromatography method coupled with tandem mass spectrometry (UPLC-MS/MS) for the determination of CIP, MOX, NOR and OFL, which was used to study the effect of UVA irradiation on the photostability of studied fluoroquinolones in powdered tablets. In addition, the kinetic evaluation of the photodegradation process was carried out and photodegradation products have been identified. In the presented studies next to UPLC-MS /MS method, differential scanning calorimetry (DSC) was also used to compare changes in analyzed samples before and after irradiation.

\section{Experimental}

\section{Chemicals and reagents}

Ciprofloxacin hydrochloride monohydrate Cat. No. 910331G Fluka, Moxifloxacin hydrochloride series Strasbourg Cedex; Council of Europe - EDQM CS; Cat No. T30026 F-6081, Norfloxacin Cat. No. 9890-1G Fluka, Ofloxacin Cat. No. O8757-1G Sigma. HPLC grade methanol, acetonitrile and formic acid (98\%) were purchased from J.T. Baker. HPLC grade water was obtained from HLP 5 (HYDROLAB Poland) apparatus and was filtered through $0.2 \mu \mathrm{m}$ filter before use.

\section{Standard solution}

For method validation, solutions containing different concentrations of the examined fluoroquinolones in the range $0.04-2.00 \mathrm{mg} \mathrm{mL}^{-1}$ were prepared.

\section{Pharmaceutical preparations}

Proxacin 500 - film-coated tablet containing $500 \mathrm{mg}$ of CIP (Polfa S.A, Poland). Excipients: pregelatinized starch, microcrystalline cellulose, colloidal silica hydrated, 
magnesium stearate, croscarmellose sodium, hypromellose, macrogol 6000, titanium dioxide.

Norflox- AZU - film-coated tablet containing $400 \mathrm{mg}$ of NOR (Azupharma, Germany). Excipients: microcrystalline cellulose, hypromellose, magnesium stearate, poly (O-carboxymethyl) starch sodium salt, povidone, propylene glycol, colloidal silica anhydrous, talc, titanium dioxide.

Avelox - film-coated tablet containing $400 \mathrm{mg}$ of MOX (Bayer, Germany). Excipients: microcrystalline cellulose, croscarmellose sodium, lactose monohydrate, magnesium stearate, hypromellose, macrogol 4000, ferric oxide, titanium dioxide.

Zanocin - film-coated tablet containing $200 \mathrm{mg}$ of OFL (Ranbaxy, Indie). Excipients: microcrystalline cellulose, maize starch, lactose, magnesium stearate, polysorbate 80 , talc, colloidal silica anhydrous, sodium starch glycolate, hydroxypropylmethylcellulose, macrogol 4000, titanium dioxide.

\section{Irradiation conditions and preparation of samples}

Irradiation was conducted in a climatic chamber KBF-ICH 240 APT.line ${ }^{\text {rm; }}$; (Binder GmbH, Tuttlingen, Germany) at $20^{\circ} \mathrm{C}$ and $60 \%$ relative humidity using UVA radiation (320-400 nm) with maximum emission at $365 \mathrm{~nm}$. The distance of the samples to radiation source was $13 \mathrm{~cm}$. The UVA dose was determined by means of radiometer type VLX-3 W, Vilber Lourmat, with a sensor CX-365, to be each time of $5.09 \times 10^{-3} \mathrm{~J} \mathrm{~cm}^{-2} \mathrm{~min}^{-1}$.

Powdered tablet in the amount of $50.0 \mathrm{mg}$ was distributed evenly on a quartz Petri dish with a diameter of $5 \mathrm{~cm}$, covered with a quartz cover and placed in the climatic chamber. The samples were exposed to UVA radiation from 7 to 113 days.

For each sample a dark control sample was prepared, which was protected with aluminum foil before irradiation.

After exposure specified number of days the tablet powder was extracted with methanol and diluted to obtain a solution having a concentration of $1.00 \mathrm{mg} \mathrm{mL}^{-1}$.

\section{UPLC/MS/MS analysis}

The UPLC-MS/MS system consisted of a Waters ACQUITY $^{\bullet}$ UPLC $^{\ominus}$ (Waters Corporation, Milford, MA, USA) coupled to a Waters TQD mass spectrometer (electrospray ionization mode ESI-tandem quadrupole). Chromatographic separations were carried out using the Acquity UPLC BEH (bridged ethyl hybrid) $\mathrm{C}_{18}$ column; $2.1 \times 100 \mathrm{~mm}$, and $1.7 \mu \mathrm{m}$ particle size. The column was maintained at $40^{\circ} \mathrm{C}$. The following gradient was used: 0 min, $95 \%$ of eluent $\mathrm{A}$ and $5 \%$ of eluent B; $10 \mathrm{~min}, 0 \%$ of eluent A and $100 \%$ of eluent B, at a flow rate of $0.3 \mathrm{~mL} \mathrm{~min}^{-1}$. Eluent A: $0.1 \%(\mathrm{v} / \mathrm{v})$ formic acid in water; eluent B: $0,1 \%(\mathrm{v} / \mathrm{v})$ formic acid in acetonitrile. Chromatograms were recorded using Waters e $\lambda$ PDA detector. Compound concentration (\%i) after photodegradation was calculated from quotient of peak area (Ai) to the sum of all peak areas $(\Sigma \mathrm{A})$ on chromatograms according to formulation $\% \mathrm{i}=(\mathrm{Ai} / \Sigma \mathrm{A}) 100$ at $\lambda=$ $294 \mathrm{~nm}$. Spectra were analyzed in $200-700 \mathrm{~nm}$ range with $1.2 \mathrm{~nm}$ resolution and sampling rate 20 points/s. MS detection settings of Waters TQD mass spectrometer were as follows: source temperature $150^{\circ} \mathrm{C}$, desolvation temperature $350^{\circ} \mathrm{C}$, desolvation gas flow rate $600 \mathrm{~L} \mathrm{~h}^{-1}$, cone gas flow $100 \mathrm{~L} \mathrm{~h}^{-1}$, capillary potential $3.00 \mathrm{kV}$, cone potential $20 \mathrm{~V}$. Nitrogen was used for both nebulizing and drying gas. The data were obtained in a scan mode ranging from 50 to $1000 \mathrm{~m} / \mathrm{z}$ in time $0.5 \mathrm{~s}$ intervals; 8 scans were summed up to get the final spectrum. Collision activated dissociations (CAD) analyses were carried out with the energy of $30 \mathrm{eV}$, and all the fragmentations were observed in the source. Consequently, the ion spectra were obtained by scanning from 50 to $600 \mathrm{~m} / \mathrm{z}$ range. Data acquisition software was MassLynx V 4.1 (Waters).

\section{DSC analysis}

The DSC measurement were performed in an atmosphere of nitrogen with a flow rate of $50 \mathrm{~mL} \mathrm{~min}^{-1}$ using EXTAR DSC 7020 apparatus (SII NanoTechnology Inc.) equipped with DSC 7020 electric cooling unit. The temperature calibration was done with indium and tin (melting temperature $\mathrm{T}_{\mathrm{m}}$ of In was $156.6^{\circ} \mathrm{C}, \mathrm{T}_{\mathrm{m}}$ of Sn was $231.88^{\circ} \mathrm{C}$ ). The calibration of enthalpy change was done with tin (melting enthalpy $\Delta \mathrm{H}_{\mathrm{m}}$ of $\mathrm{Sn}$ was $60.46 \mathrm{~J} \mathrm{~g}^{-1}$ ).

The samples of about 4.0 to $4.9 \mathrm{mg}$ were correctly weighed in an aluminum pans and sealed. Then the pans were equilibrated at $30^{\circ} \mathrm{C}$ for $15 \mathrm{~min}$ and thereafter the melting behavior were analyzed at heating rate of $10^{\circ} \mathrm{C}$.

\section{Validation of UPLC/MS/MS method}

The described method was validated for the determination of CIP, MOX, NOR and OFL in the presence of photodegradation products by UPLC method according to $\mathrm{ICH}$ guidelines [14]. To demonstrate the specificity of the developed UPLC method the solutions of CIP, MOX, NOR, OFL after photodegradation were analyzed. Peak purity test was carried out for CIP, MOX, NOR, OFL peaks by using MS detector in stressed sample. The system suitability parameters were defined with respect to resolution of examined fluoroquinolones peaks using solutions of CIP, MOX, NOR, OFL, after photodegradation. The linearity for CIP, MOX, NOR, OFL was assessed by injecting six separately prepared solutions covering the range of $0.18-2.00 \mathrm{mg} \mathrm{mL}^{-1}$. The slope of regression line, $\mathrm{y}$-intercept, standard deviation of slope and intercept, correlation coefficient, $\mathrm{R}^{2}$ value and standard error of residuals of the calibration curve were calculated using the program Statistica v. 10. Next, to determine whether the 
residuals have normal distribution, the Shapiro-Wilk statistical test was used. Based on the standard error of residuals (Se) and the slope (a) of the calibration plots and following the formula $\mathrm{LOD}=3.3 \mathrm{Se} / \mathrm{a}$ and $\mathrm{LOQ}=10 \mathrm{Se} / \mathrm{a}$, the LOD and LOQ for examined fluoroquinolones were estimated. The repeatability of the method was checked by a sixfold analysis of the concentration level $1.00 \mathrm{mg} \mathrm{mL}^{-1}$ of CIP, MOXI, NOR, OFL solutions. The same protocol was followed for three different days to study the intermediate precision of the proposed method. Different analysts prepared different solutions on different days. The RSD (\%) of the peak area of examined fluoroquinolones was calculated. To demonstrate the robustness of the method deliberate small changes of flow rate, content of acetonitrile and column temperature were made around the optimal values. The mobile phase flow rate was $0.30 \mathrm{~mL} \mathrm{~min}{ }^{-1}$; to study the effect of the flow rate on resolution, the flow rate was changed to 0.27 and $0.33 \mathrm{~mL} \mathrm{~min}^{-1}$. The effect of the column temperature was studied at $36^{\circ} \mathrm{C}$ and $44^{\circ} \mathrm{C}$ (instead of $40^{\circ} \mathrm{C}$ ).

\section{Results and discussion}

Photochemical reactivity of pharmaceutical substances is important in drug formulation technology. Undesirable changes in the pharmaceutical products induced by UV-VIS irradiation may occur not only during the production of active pharmaceutical ingredient (API), but also during the preparation of dosage form or during storage [15-17]. Literature data indicate that the stability of pharmaceutical substances also depends on the application of appropriate excipients [12]. Drug forms are designed by manufacturers to maintain the quality of pharmaceuticals under the storage conditions. However, the tablets are sometimes pulverized to powders in clinical use to make them easy to ingest for elderly or disabled persons if they cannot be consumed in their whole form [18].

The current guidelines of the International Conference on Harmonization ( $\mathrm{ICH}$ ) require the development of stability-indicating assay methods suitable for the determination of drugs [14].

\section{Method validation}

Herein we developed a universal UPLC-MS/MS stabilityindicating method for the separation, identification and determination of examined fluoroquinolones in the presence of its photodegradation products. The method was used for the kinetic studies of CIP, MOX, NOR and OFL.

The developed UPLC method was specific to examine fluoroquinolones and guaranteed obtaining well shaped peaks both for active substances and coexisting photodegradation products. Peaks of main components were quite well resolved from photodegradation products in chromatograms and no interference that could have an influence on the obtained results was possible (Table 1 ). The main peak purity was examined with MS spectra using CODA algorithm (Waters Corporation, Milford, MA, USA). The investigated MS spectra uniquely contained signals corresponding to the examined fluoroquinolones and solvent. Satisfactory resolution was

Table 1 Validation of the method

\begin{tabular}{|c|c|c|c|c|}
\hline Parameter & CIP & MOX & NOR & OFL \\
\hline RT $(\min )^{a}$ & $2.52 \pm 0.05$ & $3.22 \pm 0.05$ & $2.44 \pm 0.05$ & $2.47 \pm 0.04$ \\
\hline Resolution $^{\mathrm{a}, \mathrm{b}}$ & 1.50 & 0.92 & 1.51 & 0.80 \\
\hline LOD (mg mL $\left.\mathrm{mL}^{-1}\right)$ & 0.06 & 0.06 & 0.09 & 0.10 \\
\hline LOQ (mg mL $\left.\mathrm{mL}^{-1}\right)$ & 0.18 & 0.18 & 0.26 & 0.30 \\
\hline Linear range $\left(\mathrm{mg} \mathrm{mL}^{-1}\right)$ & $0.18-2.00$ & $0.18-1.50$ & $0.26-2.00$ & $0.30-1.50$ \\
\hline \multicolumn{5}{|l|}{ Regression equation $(y)$ : } \\
\hline Slope $\left(a \pm S_{a}\right)$ & $139288.9 \pm 1140.1$ & $286408.6 \pm 3181.1$ & $166591.5 \pm 2043.2$ & $284748.3 \pm 5341.4$ \\
\hline Intercept $\left(b \pm S_{b}\right)$ & $-635.2 \pm 1176.9$ & $4474.6 \pm 2691.5$ & $-228.6 \pm 2067.2$ & $4043.2 \pm 4455.5$ \\
\hline$t=b / S_{b}$ & $\begin{array}{c}0.54<t_{a, f} \text { statistically } \\
\text { insignificant }\end{array}$ & $\begin{array}{c}1.66<t_{a, f} \text { statistically } \\
\text { insignificant }\end{array}$ & $\begin{array}{c}0.11<\mathrm{t}_{\mathrm{a}, \mathrm{f}} \text { statistically } \\
\text { insignificant }\end{array}$ & $\begin{array}{c}0.91<t_{a, f} \text { statistically } \\
\text { insignificant }\end{array}$ \\
\hline $\begin{array}{l}\text { Normality of residuals }{ }^{c} \\
\text { (Shapiro-Wilk test) }\end{array}$ & $0.9343(p=0.49)$ & $0.9619(p=0.81)$ & $0.9387(p=0.54)$ & $0.9462(p=0.62)$ \\
\hline Correlation coefficient & 0.9997 & 0.9995 & 0.9994 & 0.9986 \\
\hline $\mathrm{R}^{2}$ value & 0.9994 & 0.9989 & 0.9986 & 0.9968 \\
\hline Precision (\% RSD) & 1.04 & 0.74 & 1.09 & 0.64 \\
\hline Intermediate precision (\% RSD) & 1.30 & 0.99 & 1.18 & 0.80 \\
\hline \multicolumn{5}{|c|}{$\begin{array}{l}\text { Regression equation } y=a c+b ; c-\text { concentration of solution; } y \text { - peak area; } S_{a} \text { - standard deviation of slope; } S_{b}-\text { standard deviation of intercept, } t \text { - calculated value } \\
\text { of Student's } t \text {-test, } t_{a, f}=2.776 \text { critical value of Student's t-test for degrees of freedom } f=4 \text { and significance level } a=0.05 \text {; } \\
{ }^{a} M e a n \pm S D(n=6) \text {. } \\
{ }^{b} \text { Resolutions were calculated between two adjacent peaks. } \\
{ }^{c} \text { normal distribution of residuals if } p>0.05 \text {. }\end{array}$} \\
\hline
\end{tabular}



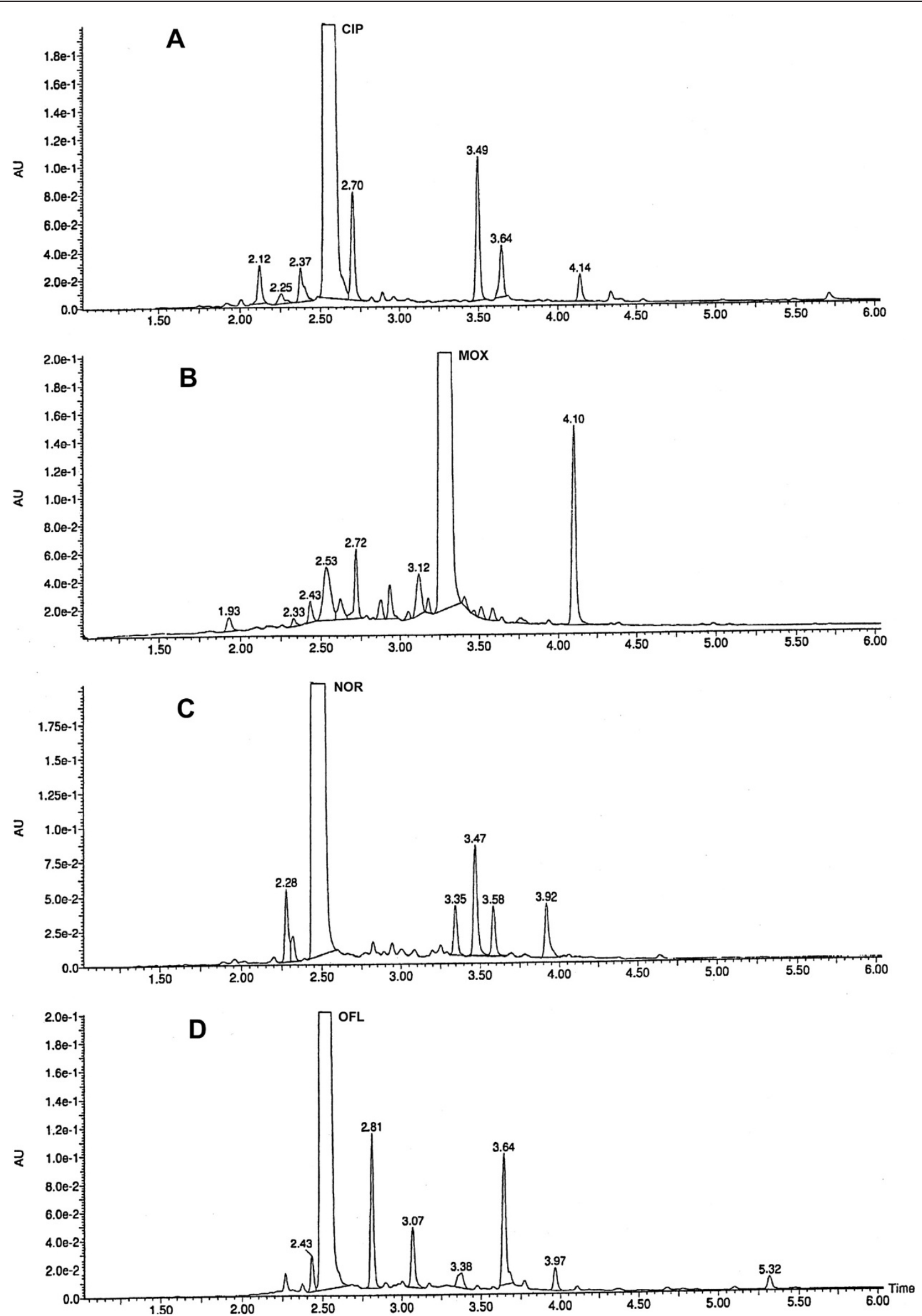

Figure 1 UPLC chromatograms registered for fluoroquinolones after photodegradation in solid phase in the presence of excipients: A - CIP RT = 2.53, B - MOX RT = 3.26, C - NOR RT = 2.45, D - OFL RT = 2.50. 


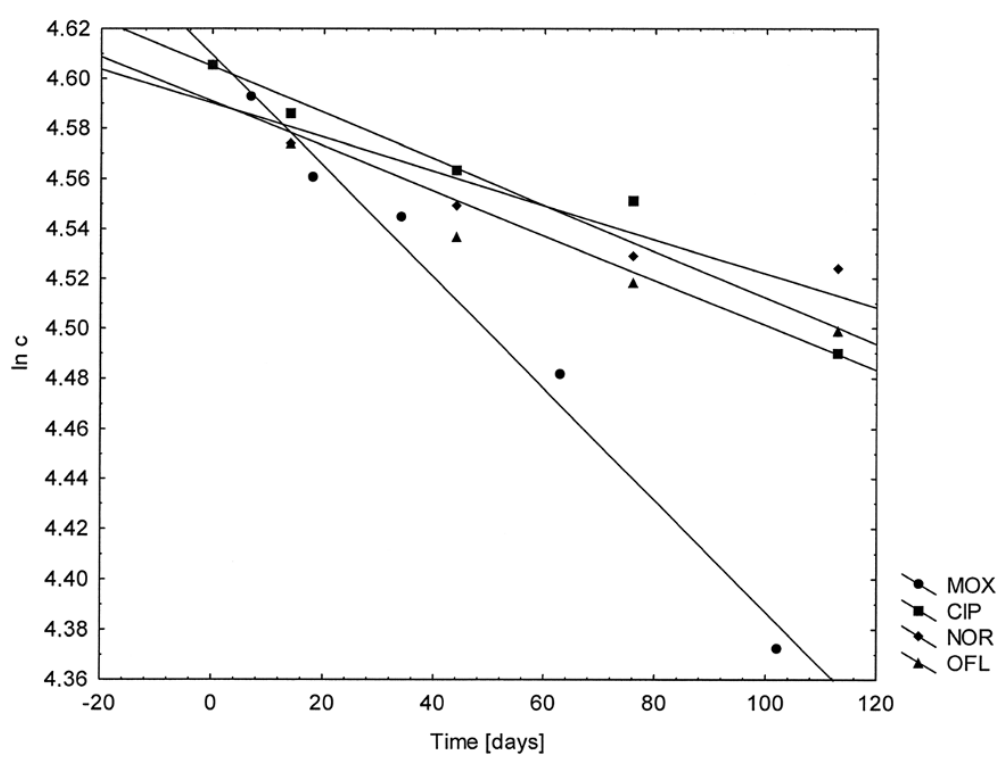

Figure 2 The $\ln c=f(t)$ graph of photodegradation of CIP, MOX, NOR and OFL.

also obtained for photodegradation products, peaks appearing in chromatograms were sufficiently well resolved and could be analyzed by mass spectrometry (Figure 1).

Regression analysis results obtained for examined fluoroquinolones are presented in Table 1 . The correlation coefficients (R) and determination coefficients $\left(R^{2}\right)$ obtained for linear model for all examined fluoroquinolones were greater than 0.999 . The y-intercepts of the linear equation for CIP, MOX, NOR and OFL were statistically insignificant. The distribution of the residuals can well be approximated with a normal distribution as it is shown by $\mathrm{p}$-values $(\mathrm{p}>0.05)$ of the Shapiro-Wilk normality test. Based on regression analysis, it was assumed that the calibration data fitted well to linear model. Linearity range was observed in the wide concentration range $0.18-2.00 \mathrm{mg} \mathrm{mL}^{-1}$ for CIP, $0.18-1.50 \mathrm{mg} \mathrm{mL}^{-1}$ for MOX, $0.26-2.00 \mathrm{mg} \mathrm{mL}^{-1}$ for NOR and 0.30 $1.50 \mathrm{mg} \mathrm{mL}^{-1}$ for OFL.

Sensitivity of the method was good. The LOD and LOQ values were found to be from 0.060 to $0.10 \mathrm{mg} \mathrm{mL}^{-1}$ and from 0.18 to $0.30 \mathrm{mg} \mathrm{mL}^{-1}$, respectively. Good precision and intermediate precision with \%RSD less than $2.0 \%$ was observed. Detailed results were presented in Table 1. In all the deliberately varied chromatographic conditions (flow rate, column temperature), examined fluoroquinolones and degradation products were adequately resolved, and the order of elution remained unchanged.

\section{Photodegradation of examined fluoroquinolones in presence of excipients}

The stability of the dosage form is different than API occurring separately, and therefore the stability studies for both forms are justified. In the case of tablets, pharmaceutical product contains additives that may affect the stability of the drug by speeding up or slowing down the degradation process.

In the available literature, only a few papers presenting the problem of photodegradation of the active ingredients in the presence of excipients in the solid phase are known [12]. Studies of the effect of UVA irradiation on the CIP, MOX, NOR and OFL in the solid phase in the presence of excipients from the tablets have shown that analyzed substances undergo photodegradation and differences occurring in the chromatograms concern only the number of peaks, peak area and RT values. However, no changes in the dark control samples were observed.

Photodegradation of CIP and OFL leads to formation of six photodegradation products CP-1 - CP- 6 and OP-1 OP-6, (Figure $1 \mathrm{~A}$ and $\mathrm{D}$ ), whereas in the case of NOR five photodegradation products were identified NP-1 - NP-5 (Figure $1 \mathrm{C}$ ). Peak areas of individual products increase with increasing exposure time. Photodegradation of MOX is significantly different compared with CIP, NOR and OFL because different number of decomposition products MP-1 and MP-10 (Figure 1B) appears during degradation process. Percentage amount of active substances in chromatograms also changes in a different way.

Table 2 The kinetic results of photodegradation

\begin{tabular}{lcccc}
\hline Component & $\mathbf{k}$ [days $^{-1}$ ] & $\mathbf{t}_{\mathbf{0 . 1}}$ [days] & $\mathbf{t}_{\mathbf{0 . 5}}$ [days] & $\begin{array}{c}\text { Correlation } \\
\text { coefficient } \mathbf{r}\end{array}$ \\
\hline CIP & $0.9 \times 10^{-3}$ & 117.00 & 770.00 & 0.9721 \\
\hline MOX & $2.2 \times 10^{-3}$ & 47.86 & 315.00 & 0.9936 \\
\hline NOR & $0.7 \times 10^{-3}$ & 150.43 & 990.00 & 0.9330 \\
\hline OFL & $0.9 \times 10^{-3}$ & 117.00 & 770.00 & 0.9619 \\
\hline
\end{tabular}


Table 3 Products of photodegradation of CIP<smiles>O=C(O)c1cn(C2CC2)c2cc(N3CC=NCC3)c(F)cc2c1=O</smiles>
\begin{tabular}{lll}
\hline CP-2 & 2.25 & 378.1
\end{tabular}<smiles>NC(=O)CN(CC(=O)O)c1cc2c(cc1F)c(=O)c(C(=O)O)cn2C1CC1</smiles><smiles>O=C(O)c1cn(C2CC2)c2cc(N3CC[NH2+]C(O)C3)c(F)cc2c1=O</smiles><smiles>O=C1CN(c2cc3c(cc2F)c(=O)c(C(=O)O)cn3C2CC2)CC(O)N1</smiles><smiles>CC[NH+]([O-])c1cc2c(cc1F)c(=O)c(C(=O)O)cn2C1CC1</smiles>

Table 3 Products of photodegradation of CIP (Continued)<smiles>CNc1cc2c(cc1F)c(=O)c(C(=O)O)cn2C1CC1</smiles>

Photodegradation of CIP was $15.56 \%$, OFL $11.91 \%$ and NOR $10.18 \%$ after 113 days of exposure, and for MOX $21.56 \%$ after 105 days of exposure.

Comparing the excipients present in the tested pharmaceutical preparation some certain similarities and differences regarding the inorganic components, which may be involved in the photodegradation process can be observed. The presence of $\mathrm{TiO}_{2}$ in the tablet mass in all tested pharmaceutical preparations and the presence of $\mathrm{Fe}_{2} \mathrm{O}_{3}$ in MOX pharmaceutical preparation is interesting from the photochemical point of view.

Titanium dioxide is one of the compounds having the ability to process the photon energy into chemical energy [19] and the Fe (III) ions, which may undergo an irreversible reduction during irradiation are considered as photosensitizers in photochemical reactions $[20,21]$.

In the available literature manuscripts describing the increase in the efficiency of photo-degradation under the influence of the photocatalytic system $\mathrm{TiO} 2 / \mathrm{Fe}$ (III) salt in comparison with the action of these compounds present separately are known [22,23].

The effect of $\mathrm{Fe}_{2} \mathrm{O}_{3}$ and $\mathrm{TiO}_{2}$ present in the MOX tablet mass on the acceleration of photodegradation compared to other fluoroquinolones in which there is only $\mathrm{TiO}_{2}$ can not therefore be excluded. The observed differences in photodegradation process may also be dependent on the chemical structure of individual fluoroquinolones.

\section{Kinetic evaluation}

The analysis of the equation $\ln \mathrm{c}=\mathrm{f}(\mathrm{t})$ for the photodegradation of CIP, MOX, NOR and OFL revealed that the process followed the kinetics of first order reaction (Figure 2).

Depending on the type of fluoroquinolone, distribution of the obtained results was observed (correlation coefficient $\mathrm{R}$ was from 0.9530 to 0.9936 ), which may be due to the presence of excipients that may reduce the intensity of radiation absorbed by the tested compounds.

The calculated reaction rate constants $\mathrm{k}$ take different values from the smallest for NOR, higher for CIP and OFL to the largest for MOX. Visible differences in 
Table 4 Products of photodegradation of MOX

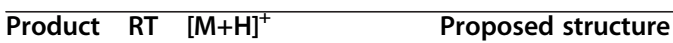

Id

\begin{tabular}{lll}
\hline MP-1 & 1.93 & 252.1
\end{tabular}<smiles>COc1c(N)c(F)cc2c1N(C1CC1)CCC2O</smiles>

\begin{tabular}{lll}
\hline MP-2 & 2.33 & 432.1
\end{tabular}<smiles>COc1c(N2C(=O)C3CCCNC3C2O)c(F)cc2c(=O)c(C(=O)O)cn(C3CC3)c12</smiles>

\begin{tabular}{lll}
\hline MP-3 & 2.43 & 416.1
\end{tabular}<smiles>COc1c(N2CC3NCCCC3C2=O)c(F)cc2c(=O)c(C(=O)O)cn(C3CC3)c12</smiles>

\begin{tabular}{lll}
\hline MP-4 & 2.53 & 418.1
\end{tabular}<smiles>COc1c(N2CC3NCCCC3C2O)c(F)cc2c(=O)c(C(=O)O)cn(C3CC3)c12</smiles>

\begin{tabular}{lll}
\hline MP-5 & 2.62 & 365.1
\end{tabular}<smiles>COc1c(F)cc2c(=O)c(C(=O)O)cn(C3CC3)c2c1OCC(=O)O</smiles>

\begin{tabular}{lll}
\hline MP-6 & $2.72 \quad 418.1$
\end{tabular}<smiles>COc1c(N2CC3CCCNC3(O)C2)c(F)cc2c(=O)c(C(=O)O)cn(C3CC3)c12</smiles>

Table 4 Products of photodegradation of MOX (Continued)

\begin{tabular}{lll}
\hline MP-7 & 2.88 & 442.1
\end{tabular}<smiles>COc1c(N2C(=O)C3CCC(=O)NC3(C)C2=O)c(F)cc2c(=O)c(C(=O)O)cn(C3CC3)c12</smiles>

\begin{tabular}{lll}
\hline MP-8 & 2.93 & 416.1
\end{tabular}<smiles>COc1c(N2CC3CCC(=O)NC3C2)c(F)cc2c(=O)c(C(=O)O)cn(C3CC3)c12</smiles>

\begin{tabular}{lll}
\hline MP-9 & 3.12 & 418.1
\end{tabular}<smiles>COc1c(N2CC3CCC(O)[C@@H]3C2)c(F)cc2c(=O)c(C(=O)O)cn(C3CC3)c12</smiles>

\begin{tabular}{lll}
\hline MOX & 3.26 & 402.1
\end{tabular}<smiles>COc1c(N2CC3CCCNC3C2)c(F)cc2c(=O)c(C(=O)O)cn(C3CC3)c12</smiles>

\begin{tabular}{lrr}
\hline MP-10 & 4.10 & 293.1
\end{tabular}<smiles>COc1c(N)c(F)cc2c(=O)c(C(=O)O)cn(C3CC3)c12</smiles>

photostability of tested compounds are also confirmed by $t_{0.1}$ and $t_{0.5}$ values (Table 2 ).

Analyzing the photodegradation results for CIP, MOX, NOR and OFL in the powdered tablets it can be assumed that the tablets containing NOR will be the least susceptible to photodegradation process comparing to 
tablets with CIP and OFL and almost 3 times more photostable than tablets with MOX.

\section{Identification of photodegradation products}

The identification of photoproducts of four fluoroquinolones (CIP, MOX, NOR, OFL) was performed on a basis of UPLC/MS analysis. Photodegradation products of fluoroquinolones are shown in Tables 3, 4, 5 and 6, for CIP, MOX, NOR, and OFL, respectively.

The photodegradation process was found mainly to affect 7-amine substituent, while the fluoroquinolone core remained unchanged. The only exception was MOX, which formed product of decarboxylation and partial reduction of dihydropiridine ring (MP-1).

Generally, the photodegradation proceeded with ring opening and dealkylation of 7-amine substituent of the investigated fluoroquinolones or hydroxylation in the close vicinity to nitrogen atoms in the substituent in the 7 position of the fluoroquinolones, successive oxidation to their oxo counterparts and subsequently opening the ring of the substituent.

The most abundant products were products of ring opening and dealkylation in the substituent in the 7 position, containing amine moiety (CP-6, MP-10, NP-3, OP-4) and their ethyl derivatives (CP-5, NP-2, OP-2). In case of NOR 2-aminoethyl derivative (NP-1) was also observed.

Less abundant products of the photodegradation of the fluoroquinolones were products of hydroxylation and subsequent oxidation in the close vicinity of nitrogen atoms of the substituent in the 7 position, containing one hydroxyl moiety (CP-3, MP-4, MP-6, MP-9, OP-1), their oxo counterparts (MP-3, MP-8 and OP-5), hydroxylactam moiety (CP-4, MP-2, OP-3) or multiple carbonyl groups (MP-7, NP-5).

Other routs of photodegradation led to degradation products with double bond on nitrogen in the substituent in the 7 position (CP-1), or containing partially degraded oxidized ring of that substituent (CP-2, MP-5, NP-4, OP-6).

\section{Differential Scanning Calorimetry}

The sample of powdered CIP tablets exposed to UVA shows a number of similarities and differences in comparison to the sample not exposed (Figure 3A). In the temperature range of $104-174^{\circ} \mathrm{C}$ a broad endotherm, associated with the dehydration process, is observed [24] while there is no endothermic transition at $\mathrm{T}_{\max }=238.0^{\circ} \mathrm{C}$ [25]. Moreover, there are two small endothermic peaks at $\mathrm{T}_{\max }=179.5^{\circ} \mathrm{C}$ and $\mathrm{T}_{\max }=205.5^{\circ} \mathrm{C}$ coming from the melting processes of the newly created chemical compounds. Endothermic peak of simultaneous melting and decomposition process has a smaller value of enthalpy $\Delta \mathrm{H}=12.8 \mathrm{~mJ} \mathrm{mg}^{-1}$ and has been moved toward lower temperatures of $\mathrm{T}_{\max }=$ $299.5^{\circ} \mathrm{C}$ and $\mathrm{T}_{\max }=302.1^{\circ} \mathrm{C}$.
Table 5 Products of photodegradation of NOR<smiles>CCNc1cc2c(cc1F)c(=O)c(C(=O)O)cn2CC</smiles><smiles>CCn1cc(C(=O)O)c(=O)c2cc(F)c(N)cc21</smiles><smiles>CCn1cc(C(=O)O)c(=O)c2cc(F)c(NC(=O)C=O)cc21</smiles> 
Table 6 Products of photodegradation of OFL<smiles>CCOC(=O)OCCOc1c(F)cc2c(=O)c(C(=O)O)cn3c2c1OCC3C</smiles><smiles>CC1COc2c(N3CC[NH2+]C(O)C3)c(F)cc3c(=O)c(C(=O)O)cn1c23</smiles><smiles>CCNc1c(F)cc2c(=O)c(C(=O)O)cn3c2c1OCC3C</smiles><smiles>CC1COC2=C(NCC(=O)N(C)C(O)C2)C(F)=Cc2c(Cl)n1cc(C(=O)O)c2=O</smiles>

Table 6 Products of photodegradation of OFL (Continued)<smiles>CC1COc2c(N)c(F)cc3c(=O)c(C(=O)O)cn1c23</smiles>

The DSC curves of powdered NOR tablets, before and after UVA irradiation (Figure 3B), show a significant temperature $T_{\text {onset }}$ and $T_{\max }$ shifts and a reductions of the corresponding values of enthalpy $\Delta \mathrm{H}$. The maximum temperature of endothermic peak corresponding to the maximum of the first stage of decomposition [26] was moved to $126.0^{\circ} \mathrm{C}$ and the enthalpy decreased to $\Delta \mathrm{H}=$ $179.0 \mathrm{~mJ} \mathrm{mg}^{-1}$. The next endothermic peak, describing the melting process $\mathrm{T}_{\text {onset }}=220.3^{\circ} \mathrm{C}$ [27], was also changed. The value of enthalpy $\Delta \mathrm{H}$ decreased to $21.6 \mathrm{~mJ} \mathrm{mg}^{-1}$ and the melting temperatures $\mathrm{T}_{\text {onset }}$ and $\mathrm{T}_{\max }$ are $191.5^{\circ} \mathrm{C}$ and $206.7^{\circ} \mathrm{C}$ respectively. The endoand exothermic peaks located at the end of the DSC curves show different shapes. The exothermic peak presented in the not irradiated sample at $\mathrm{T}_{\max }=151.6^{\circ} \mathrm{C}$ was not found.

The DSC curve of MOX powdered tablets exposed to UVA shows the broadest changes compared to the corresponding not exposed sample (Figure $3 \mathrm{C}$ ). One can see the absence of the last melting peak [28] at $\mathrm{T}_{\text {onset }}=$ $231.2^{\circ} \mathrm{C}$ and a rapid growth of a jagged baseline with tiny spikes. This observations suggest that the decomposition of the sample starts much earlier. Endothermic transitions at $\mathrm{T}_{\max } 209.1^{\circ} \mathrm{C}$ and $170.6^{\circ} \mathrm{C}$ was moved toward lower values $198.6^{\circ} \mathrm{C}$ and $161.3^{\circ} \mathrm{C}$. The enthalpies decreased as well. The peak at $\mathrm{T}_{\max }=146.1^{\circ} \mathrm{C}$ remains unchanged both for the temperature $\mathrm{T}_{\text {onset }}$ and $\Delta \mathrm{H}$ values. Particularly noteworthy is a small endothermic process that occurs in the $\mathrm{T}_{\max }=120.9^{\circ} \mathrm{C}$, which is probably related to the decomposition of the sample.

In contrast to the MOX, NOR and CIP the OFL compound seems to be more thermally stable and its decomposition, associated with weight loss, starts just after reaching the melting point $\mathrm{T}=264.8^{\circ} \mathrm{C}$ [29]. The DSC curves obtained for powdered UVA irradiated and not irradiated tablets are not corresponding to each other (Figure 3D). While there is no endothermic melting peak at $\mathrm{T}_{\text {onset }}=266.2^{\circ} \mathrm{C}$, the new, small one at $\mathrm{T}_{\max }=138.0^{\circ} \mathrm{C}$ is observed. This peak could be considered as a degradation product. The peak at temperature of $\mathrm{T}_{\text {onset }}=180.1^{\circ} \mathrm{C}$ and $\Delta \mathrm{H}=28.2$ and $\mathrm{mJ} \mathrm{\textrm {mg } ^ { - 1 }}$, under the influence of UVA 

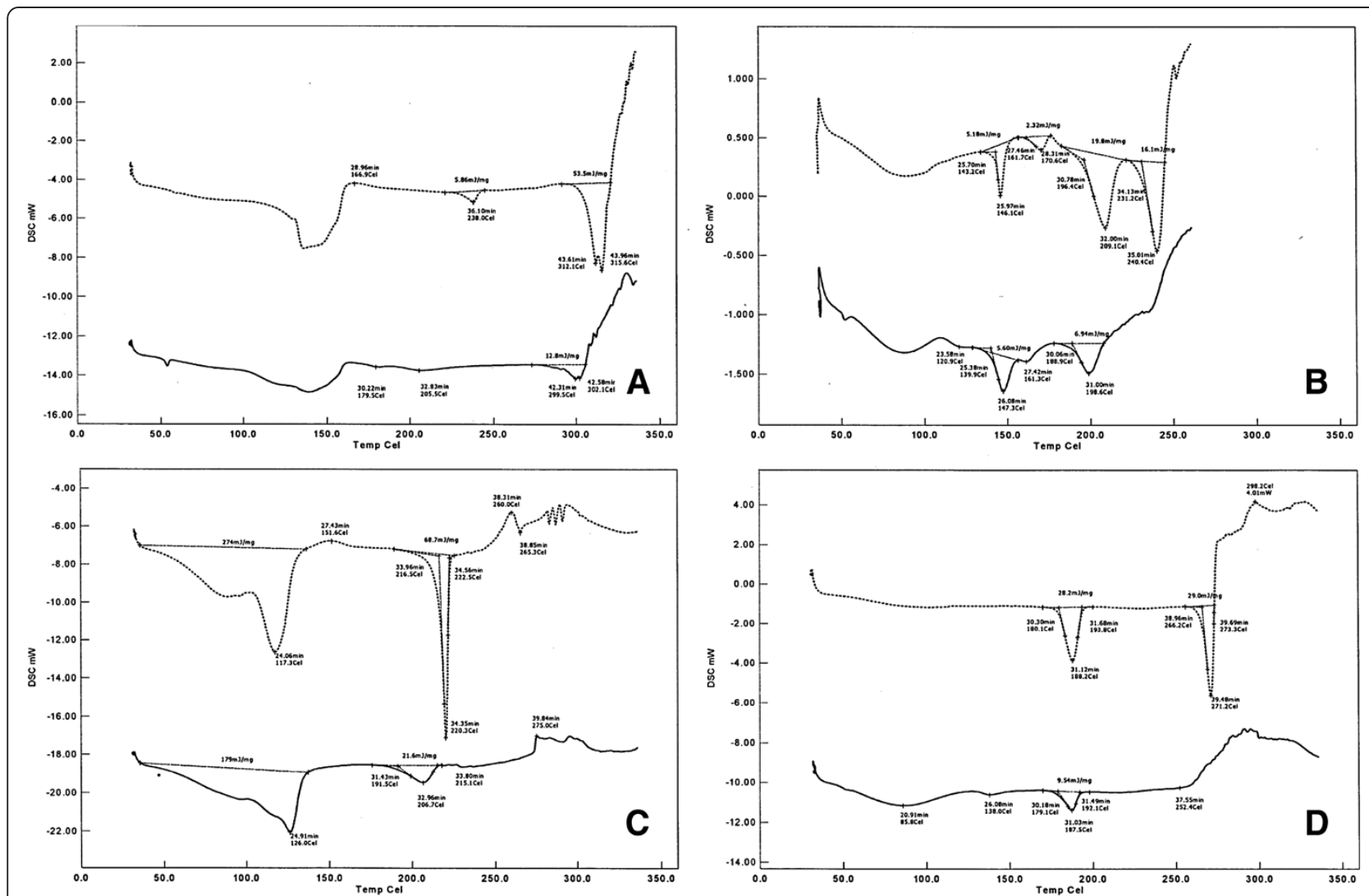

Figure 3 The DSC curves of the examined fluoroquinolones; dotted line: before exposure and continuous line: after exposure to UVA; A - CIP, B - MOX, C - NOR, D - OFL.

light, significantly reduced the value of enthalpy to $\Delta \mathrm{H}=$ $9.54 \mathrm{~mJ} \mathrm{mg}^{-1}$ (Figure 3D).

Summing up these part of studies, one can see that DSC curves obtained for samples exposed to UVA light differ significantly from those not exposed. The broadest changes, comparing to the CIP, NOR and OFL, concerned the MOX, what confirms the results obtained by UPLC-MS/MS method.

\section{Conclusions}

The developed UPLC-MS/MS method enables the determination of CIP, MOX, NOR and OFL in the presence of photodegradation products and identification of photodegradation products. The method meets the acceptance criteria for validation which guarantees correct analysis results. It has been shown that the tested fluoroquinolones occurring in the presence of excipients undergo photodegradation under the influence of UVA radiation. Photodegradation follows the kinetics of a first order reaction. The results obtained by UPLC-MS/MS and the calculated kinetic parameters $\mathrm{k}$ and $\mathrm{t}_{0.1}$ and $\mathrm{t}_{0.5}$ have shown that photodegradation of MOX is faster than CIP, NOR and OFL. Greater susceptibility of MOX to photodegradation process has also been shown by
DSC method. It seems that the differences obtained during the photodegradation of tested fluoroquinolones may be connected with the presence of inorganic components in the tablet powder such as $\mathrm{Fe}_{2} \mathrm{O}_{3}$ and $\mathrm{TiO}_{2}$.

\section{Abbreviations}

API: Active pharmaceutical ingredient; A: The slope of regression line; CAD: Collision activated dissociations; CIP: Ciprofloxacin; DSC: Differential scanning calorimetry; ESI: Electrospray ionization; $\Delta \mathrm{H}$ : Enthalpy; K: Reaction rate constants; LOD: Limit of detection; LOQ: Limit of quantitation;

MOX: Moxifloxacin; MS/MS: Tandem mass spectrometry; NOR: Norfloxacin; OFL: Ofloxacin; RT: Retention time; R: Correlation coefficient;

$\mathrm{R}^{2}$ : Determination coefficient; RSD: Relative standard deviation; Se: Standard error of residuals; UPLC: Ultra-performance liquid chromatography.

\section{Competing interests}

The authors declare that they have no competing interests.

\section{Authors' contributions}

UH: Participated in the experimental designing, method validation, results discussion and writing of the manuscript. PŻ: Participated in experimental work and establishing the structure of the degradation products. PT: Performed experimental work by DSC method and contributed in results discussion. BZ̈-W: contributed in reviewing the literature, and experimental work. JK: contributed in results discussion and revised the manuscript. All authors have read and approved the final manuscript. 


\section{Acknowledgments}

The authors extend their appreciation to the Dean of Faculty of Pharmacy Jagiellonian University for funding the work through the research project No. K/ZDS/003309.

\section{Author details}

${ }^{1}$ Department of Inorganic and Analytical Chemistry, Jagiellonian University Medical College, Faculty of Pharmacy, 9 Medyczna Street, 30-688 Kraków Poland. ${ }^{2}$ Department of Medicinal Chemistry, Jagiellonian University Medica College, Faculty of Pharmacy, 9 Medyczna Street, 30-688 Kraków, Poland.

Received: 19 April 2013 Accepted: 15 July 2013

Published: 31 July 2013

\section{References}

1. Sharma PCH, Jain A, Jain S: Fluoroquinolone antibacterials: a revive on chemistry, microbiology and therapeutic prospects. Acta Pol Pharm Drug Res 2009, 66:587-604

2. Carlucci G: Analysis of fluoroquinolones in biological fluids by highperformance liquid chromatography. J Chromatogr A 1998, 812:343-367.

3. Zhanel GG, Ennis K, Vercaigne L, Walkty A, Gin AS, Embil J, Smith H, Hoban DJ: A critical review of the fluoroquinolones: focus on respiratory infections. Drugs 2002, 62:13-59.

4. Balfour JA, Lamb HM: Moxifloxacin: a review of its clinical potential in the management of community - acquired respiratory tract infections. Drugs 2000, 59:115-139.

5. Andriole VT: The quinolone: past, present, and future. Clin Infect Dis 2005, 41:113-119.

6. Philips $\mathrm{G}$, Johnson BE, Ferguson J: The loss of antibiotic activity of ciprofloxacin by photodegradation. J Antimicrob Chemiother 1990, 26:783-789.

7. Lovdahl MJ, Priebe SR: Characterization of clinafloxacin photodegradation products by LC-MS:MS and NMR. J Pharm Biomed Anal 2000, 23:521-534.

8. de Vries H, van Henegouwen GMJ B: Photochemical decomposition of lomefloxacin in vitro and in vivo. J Photochem Photobiol B: Biology 2000, 58:6-12.

9. Araki T, Kawai $Y$, Ohta I, Kitaoka H: Photochemical behavior of sitafloxacin, fluoroquinolone antibiotic, in an aqueous solution. Chem Pharm Bull 2002, 50:229-234.

10. Hubicka U, Krzek J, Żuromska B, Walczak M, Żylewski M, Pawłowski D: Determination of photostability and photodegradation products of moxifloxacin in the presence of metal ions in solutions and solid phase. Kinetics and identification of photoproducts. Photochem Photobio/ Sci 2012, 11:351-357.

11. Hubicka $U$, Krzek J: Effect of selected metal ions on the photodegradation of ciprofloxacin in solid phase. J AOAC Int 2008, 91:1331-1338.

12. Córdoba-Borrego M, Córdoba-Diaz M, Córdoba-Diaz D: Validation method for the determination of norfloxacin and its application to stability studies (photo-stability study of norfloxacin). J Pharm Biomed Anal 1999, 18:919-926.

13. Tonnesen HH, Brunsvik A, Loseth K, Bergh K, Gederaas OA: Photoreactivity of biologically active compounds. XVIII. Photostability of ofloxacin in the solid state and in a tablet formulation. Pharmazie 2007, 62:105-111.

14. ICH Q2 (R1), Validation of analytical procedure: text and methodology. Geneva: International Conference on Harmonization; 2005. http://www.ich.org/ fileadmin/Public_Web_Site/ICH_Products/Guidelines/Quality/Q2_R1/Step4/ Q2 R1 Guideline.pdf.

15. Ahuja S: Assuring quality of drugs by monitoring impurities. Adv Drug Deliv Rev 2007, 59:3-11

16. Bari S, Kadam B, Jaiswal Y, Shirkhedkar A: Impurity profile: significance in active pharmaceutical ingredient. Eurasian J Anal Chem 2007, 2:32-53.

17. Qiu Y, Chen Y, Zhang G, Liu L, Porter WR: Developing solid oral dosage forms: pharmaceutical theory \& practice. Academic Press 2009, 127-132.

18. Kawabe $Y$, Nakamura H, Hino E, Suzuki S: Photochemical stabilities of some dihydropyridine calcium-channel blockers in powdered pharmaceutical tablets. J Pharm Biomed Anal 2008, 47:618-624.

19. Nakata K, Fujishima A: $\mathrm{TiO}_{2}$ photocatalysis: design and applications. J Photochem Photobiol C: Photochem Reviews 2012, 13:169-189.

20. Catastini C, Sarakha M, Mailhot G, Bolte M: Iron (III) aquacomplexes as effective photocatalysts for the degradation of pesticides in homogeneous aqueous solutions. Sci Total Environ 2002, 298:219-228.
21. Baran W, Adamek E, Sobczak A, Makowski A: Photocatalytic degradation of sulfa drugs with $\mathrm{TiO}_{2}$, Fe salts and $\mathrm{TiO}_{2} / \mathrm{FeCl}_{3}$ in aquatic environment Kinetics and degradation pathway. App/ Catal B: Environ 2009, 90:516-525.

22. Karunakaran $\mathrm{C}$, Senthilvelan $\mathrm{S}: \mathrm{Fe}_{2} \mathrm{O}_{3}$-photocatalysis with sunlight and UV light: oxidation of aniline. Electrochem Commun 2006, 8:95-101.

23. Zhang L, Li P, Gong Z, Oni A: Photochemical behavior of benzo[a]pyrene on soil surfaces under UV light irradiation. J Environ Sci 2006, 18:1226-1232.

24. Silva-Júnior AA, Scarpa MV, Pestana KC, Mercuri LP, de Matos JR, de Oliveira AG: Thermal analysis of biodegradable microparticles containing ciprofloxacin hydrochloride obtained by spray drying technique. Thermochim Acta 2008, 467:91-98.

25. Turel I, Bukovec P: Comparison of the thermal stability of ciprofloxacin and its compounds. Thermochim Acta 1996, 287:311-318.

26. Sadeek A: Sadeek: synthesis, thermogravimetric analysis, infrared, electronic and mass spectra of $\mathrm{Mn}$ (II), $\mathrm{Co}$ (II) and Fe(III) norfloxacin complexes. J Mol Struct 2005, 753:1-12.

27. Oliveira PR, Bernardi LS, Murakami FS, Mendes C, Silva MAS: Thermal characterization and compatibility studies of norfloxacin for development of extended release tablets. J Therm Anal Calorim 2009, 97:741-745

28. Sadeek A, El-Shwiniy WH, El-Attar MS: Synthesis, characterization and antimicrobial investigation of some moxifloxacin metal complexes. Spectrochim Acta Part A 2011, 84:99-110.

29. Pintu KD, Basudev S, Soumen R: Enhancement of dissolution rate and stability study of ofloxacin solid dispersion. Der Pharmacia Sinica 2011, 2(5):169-181.

\section{doi:10.1186/1752-153X-7-133}

Cite this article as: Hubicka et al: Photodegradation assessment of ciprofloxacin, moxifloxacin, norfloxacin and ofloxacin in the presence of excipients from tablets by UPLC-MS/MS and DSC. Chemistry Central Journal 2013 7:133.

Publish with ChemistryCentral and every
scientist can read your work free of charge
"Open access provides opportunities to our
colleagues in other parts of the globe, by allowing
anyone to view the content free of charge."
W. Jeffery Hurst, The Hershey Company.
- available free of charge to the entire scientific community
- peer reviewed and published immediately upon acceptance
- cited in PubMed and archived on PubMed Central
- yours - you keep the copyright
Submit your manuscript here:
http://www.chemistrycentral.com/manuscript/

